\title{
Application of superheated water as a soil remediation media: a review
}

\author{
Reihaneh Mashhadi Ebrahim ${ }^{1, *}$ \\ ${ }^{1}$ Department of chemical engineering, Islamic Azad University South Tehran Branch, Tehran, Iran
}

\begin{abstract}
Water is a unique solvent cause its highly hydrogen-bonded structure, and at room temperature it has a high boiling point for its mass, a high dielectric constant and high polarity. At the higher temperatures, its permittivity, viscosity and surface tension decreases, but diffusion rate increases. Superheated water is a general term to denote the region of the condensed phase between $100^{\circ} \mathrm{C}$ and the critical point. Liquid water at elevated temperatures above its boiling point has been used for many years as an industrial solvent and cleaning agent in applications ranging from enhancing the extraction of oil shale, the extraction of sulphur from ore bodies in the Frasch process, to degreasing. In recent years, there has been an interest in using superheated water for soil remediation. In this paper, a review on this area of application has been performed.
\end{abstract}

\section{Introduction}

Unfortunately, one of the inseparable outcomes of rapid population growth are environmental pollutions. In many cases ignoring the polluted areas or regions at risk of pollution, will have irreparable effects on the environment and subsequently on the health of the human beings. In different areas in the country, especially the oil-rich ones, the local and sometimes wide-area pollutions due to the oil spill or carelessness in oil compounds transfer can be seen. Chemical industries, despite having so many benefits for providing welfare and comfort for the life of modern man can cause different diseases, including cancer, by entering the food cycle of humans; As in different studies, the carcinogenicity and mutagenetic effects of various hydrocarbon compounds have been proven. Soil, as the basis for producing needed foodstuffs for humans, is of great importance, and sometimes is ignored by this much. Entering various pollutants directly and indirectly (through the water and air) can cause some changes in this medium, and just like other elements of nature, the soil is always acting against these changes; But sometimes, the balance of the soil is disrupted, and we face the challenge of soil pollution. In these situations, human interventions in order to help the natural clearing processes and accelerating them seem necessary [1]. Diseases including cancer, by entering the food cycle of humans; As in different studies, the carcinogenicity and mutagenetic effects of various hydrocarbon compounds have been proven. Soil, as the basis for producing needed foodstuffs for humans, is of great importance, and sometimes is ignored by this much.
Entering various pollutants directly and indirectly (through the water and air) can cause some changes in this medium, and just like other elements of nature, the soil is always acting against these changes; But sometimes, the balance of the soil is disrupted, and we face the challenge of soil pollution. In these situations, human interventions in order to help the natural clearing processes and accelerating them seem necessary [1]. In other words, soils are considered as the refiners for nature. In addition to being a food supplier, soils also have purifying properties. These properties are originated from their physical properties (water diffusion through pores), chemical properties (adsorption and evaporation), and bio-based properties (decomposition and spoilage of organic matter). Contamination of soil with different chemical wastes is one of the most important environmental issues in various areas, which, due to the toxicity, carcinogenicity, and causing mutagenetic changes, there are vast concerns regarding their presence in nature [2]. These pollutants can be adsorbed on the surface of the soil or organic particles existing in it, which can enhance their concentration and subsequently cause their entrance to the surface waters along with the surface streams. On the other hand, these compounds may enter the groundwater and consequently lead to disorder in the food cycle of plants, humans, and animals, so they must be removed from the environment in some way [3]. Soil pollution factors include four major parts:

1- Agricultural factors

2- Oil contaminants

3- Industrial activities

4- Trash

\footnotetext{
* Corresponding author: negahaneh@yahoo.com
} 
Regarding the soil pollution in Iran, according to the statistics, a few percent of industrial and domestic effluents are refined, and the major part of industrial and domestic effluents are discharged to the environment untreated. This manner can cause soil and groundwater pollutions, which increasing the nitrate content in well waters is a clear example for such consequences. One of the soil pollutions factors, which fortunately is not common in our country is acid rain. One of the actions of the department of environment to prevent acid rain is strong opposition to the establishment of a coke factory in the Savadkuh region. The atlas of soil pollution in Iran is being prepared, which provides accurate statistics on the amount of soil pollution in the country. Up now, the following regions are reported to be the most polluted regions in Iran: Isfahan province, south of Tehran, Asaluyeh in Bushehr, lands in the vicinity of the Mes-e Sarcheshmeh, Sistan and Baluchestan province, and Khuzestan province [4].

\section{Modeling}

The mass transfer mechanism of the extraction of soluble component is as follows: The soluble component attached to the solid network (by physical and chemical forces), have to be transferred to the solvent phase via liquidation or desorption. Then, the soluble component/solvent mixture diffuses to the solid surface and finally passes the static layer adjacent to the solid particles to reach the solvent phase.

Since the contents of the solid particles vary with distance and time, the diffusion coefficients of the soluble component existing in the solid particles can be determined by observing the changes of concentration in the vicinity liquid with time. There are four mass transfer steps in general, which the diffusion of the soluble component in the solid particles toward the solvent is usually the determinative step of mass transfer [36].

Initially, there is a rapid extraction period with a constant intensity, which is stable in the mass transfer and controls the resistance intensity of the mass transfer film. Then, an unstable descending step with a very lower extraction intensity occurs. In this stage, the diffusion in the solid particles controls the intensity of the extraction process [36]. In industrial operating units such as extraction, a specific component in one phase diffuses to the contact point of two phases and then enters into the other phase. Transfer of one phase to the other phase continues until the two phases reach equilibrium point [37]. The results obtained by Fick's second law were analyzed as a mathematical model. Since the modeling is performed in fluid phase, the following assumptions are considered:

1- Fluid moves with uz velocity.

2- Solid-phase is static.

3 - There is no reaction.

In the fluid phase, movement is in z-direction, so the system is differentially modeled in this direction. According to the fluid stream, the diffusion term is ignored in this direction, and the convection term is considered as the determinative factor and described as follows:

$$
u_{z} \frac{\delta c_{i, l}}{\delta z}
$$

However, in radial direction, there is no movement, and lumped method is used for modeling, which only contains mass transfer flux:

$$
u_{z} \frac{\delta c_{i, l}}{\delta z}
$$

Now, the general relation of mass balance (inputoutput=accumulation) is shown below:

$$
k a\left(c_{i}^{*}-c_{i, l}\right)+u_{z} \frac{\delta c_{i, l}}{\delta z}+\frac{d c_{i, l}}{d t}=0
$$

The initial and boundary conditions are as follows:

$$
\begin{gathered}
c_{i, l}(0, t)=0 \\
c_{i, l}(z, 0)=0 \\
c_{i, s}(0)=c_{i, s, 0}
\end{gathered}
$$

Changes are considered only in the z-direction, and concentration variations in other directions are neglected. The following image is showing the considered system for mass balance schematically.

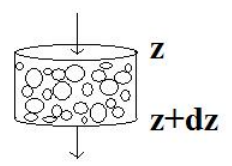

By considering a cylindrical shape element with a base area equals to the tower base area and with a height equals to $\mathrm{dz}$, the mass balance is written. At the element input, we have:

$$
N_{i, z} \cdot A
$$

Where $\mathrm{N}_{\mathrm{i}, \mathrm{z}}$, and $\mathrm{A}$ are the $\mathrm{i}$ element flux in z-direction and tower base area, respectively. At the element output, we have:

$$
N_{i, z+d z} \cdot A
$$

On the other hand, the mass transfer flux from the solid phase to gas phase is described as follows:

$$
(d z . A) k a\left(c_{i}{ }^{*}-c_{i}\right)
$$

Where $\mathrm{k}$ is the mass transfer coefficient, $\mathrm{a}$ is the specific surface area, and $\mathrm{c}_{\mathrm{i}}$ and $\mathrm{c}_{\mathrm{i}}{ }^{*}$ are the $\mathrm{i}$ component concentrations in the liquid phase and solid phase surface, respectively. By substituting the mentioned equations on this base that the total mass transfer from the gas phase to the liquid phase is equal to output rate minus input rate plus accumulation rate, we have:

$$
\frac{\partial N_{i}}{\partial z}+\frac{\partial c_{i}}{\partial t}=k a\left(c_{i}^{*}-c_{i}\right)
$$

By dividing both sides of the above equation by dz.A, the following relationship is obtained:

$$
N_{i, z+d z} A-N_{i, z} A+d z \cdot A \frac{\partial c_{i}}{\partial t}=(d z A) k c\left(c_{i}^{*}-c_{i}\right)
$$

By considering the below equation: 


$$
N_{i}=u_{z} c_{i}+J_{i}
$$

Furthermore, by defining $\mathrm{J}_{\mathrm{j}}$ as follows:

$$
J_{i}=-D_{l} \frac{\partial c_{i}}{\partial z}
$$

In the above equations, $\mathrm{u}_{\mathrm{z}}$ and $\mathrm{D}_{1}$ are the fluid velocity in the z-direction and the axial distribution coefficient. By substituting the above equations, we will have:

$$
\frac{\partial\left(u_{z} c_{i}\right)}{\partial z}-\frac{\partial}{\partial z}\left(D_{l} \frac{\partial c_{i}}{\partial z}\right)+\frac{\partial c_{i}}{\partial t}=k a\left(c_{i}^{*}-c_{i}\right)
$$

By assuming that the axial distribution coefficient does not depend on z-direction, we will have:

$$
c_{i} \frac{\partial u_{z}}{\partial z}+u_{z} \frac{\partial c_{i}}{\partial z}-D_{l} \frac{\partial^{2} c_{i}}{\partial z^{2}}+\frac{\partial c_{i}}{\partial t}=k a\left(c_{i}^{*}-c_{i}\right)
$$

By considering the continuity equation and assuming that the fluid density is constant:

$$
\frac{\partial u_{x}}{\partial x}+\frac{\partial u_{y}}{\partial y}+\frac{\partial u_{z}}{\partial z}=0
$$

Since the velocity in $\mathrm{x}$ and $\mathrm{y}$ directions are zero, the above equation turns into the following equation:

$$
\frac{\partial u_{z}}{\partial z}=0
$$

Finally, we have:

$$
\frac{\partial c_{i}}{\partial t}=D_{l} \frac{\partial^{2} c_{i}}{\partial z^{2}}-u_{z} \frac{\partial c_{i}}{\partial z}+k a\left(c_{i}^{*}-c_{i}\right)
$$

The above equation is the one to be solved. To solve such an equation, two boundary conditions and one initial condition are needed.

The boundary conditions are described as follows:

$$
\begin{aligned}
& c_{i}(0, t)=0 \\
& \frac{\partial c_{i}(z, t)}{\partial z}=0
\end{aligned}
$$

The initial condition is determined as follows:

$$
c_{i}(z, 0)=0
$$

In this study, the mass transfers of naphthalene, phenanthrene, fluoranthene, and pyrene from soil to the super-hot water were investigated. The information about molecular weight and solubility of these compounds are illustrated in the Table 1 [38].

$c_{i}^{*}$ is the solubility of $i$ component in groundwater. Therefore, given that the solubilities at $25^{\circ} \mathrm{C}$ can be found in literature, the solubilities at $100,150,200,250$, and $300{ }^{\circ} \mathrm{C}$ should be calculated. To calculate the solubilities, the following equation is used [36]:

$$
\ln x_{2}(T)=\frac{T_{0}}{T} \ln x_{2}\left(T_{0}\right)+15\left(\frac{T}{T_{0}}-1\right)^{3}
$$

Where $\mathrm{x}_{2}(\mathrm{~T})$ is the solubility at the temperature of $\mathrm{T}$ in the form of molar fraction and $\mathrm{x}_{2}\left(\mathrm{~T}_{0}\right)$ is the solubility at the specified temperature of $\mathrm{T}_{0}$, and the temperature unit is Kelvin. To calculate the $\mathrm{D}_{\mathrm{l}}$, the following equation is used:

$$
D_{l}=\frac{u d_{p}}{\varepsilon P e}
$$

Table 1. The information of the compounds used in this study.

\begin{tabular}{cccc}
\hline Compound & $\begin{array}{c}\text { Molecular } \\
\text { weight }\end{array}$ & $\begin{array}{c}\text { Solubility in water } \\
\text { at } 25^{\circ} \mathrm{C}(\mathrm{mg} / \mathrm{L})\end{array}$ & $\begin{array}{c}\text { Molecular volume } \\
\left(\mathrm{m}^{3} / \mathrm{kmol}\right)\end{array}$ \\
\hline Naphthalene & 2.128 & 32 & 407.0 \\
Phenanthrene & 2.178 & 3.1 & 554.0 \\
Fluoranthene & 3.202 & 2.0 & 6195.0 \\
Pyrene & 1.202 & 1.0 & 626.0 \\
\hline
\end{tabular}

Where $d_{p}$ is the particle diameter, which is considered 2 $\mathrm{mm}$ in this study, the bed height is considered $10 \mathrm{~mm}$, which is consistent with the empirical data, $\varepsilon$ is the porosity coefficient (due to the presence of particles in soil), which is considered 0.4 in this work, and " $u$ " is the entering velocity of the fluid. Four different flow rates, including 0.5 , 1, 1.5 , and $2 \mathrm{~cm}^{3} / \mathrm{min}$, are considered in this work. Moreover, Pe is the dimensionless number of Peclet and can be calculated using the following equation [24]:

$$
P e=1.634 R e^{0.265} S c^{-0.919}
$$

According to the following equations:

$$
\begin{gathered}
\operatorname{Re}=\frac{\rho u d_{p}}{\mu} \\
S c=\frac{\mu}{\rho D_{A B}}
\end{gathered}
$$

It is needed to know the viscosity and density at the specified temperatures. In order to determine these values, we use the equations below:

$$
\begin{gathered}
\rho=858.03+1.2128 T-0.0025 T^{2} \\
\mu=\exp \left(-10.2+\frac{290970}{T^{2}}\right)
\end{gathered}
$$

The units of temperature, density, and viscosity in the above equations, are Kelvin, $\mathrm{kg} / \mathrm{m}^{3}$, and Pa.S, respectively.

To calculate the diffusion coefficient $\left(\mathrm{D}_{\mathrm{AB}}\right)$, the following equation can be used:

$$
D_{A B}=\frac{\left(117.3 \times 10^{-18}\right)\left(\varphi M_{B}\right)^{0.5} T}{\mu v_{A}^{0.6}}
$$

Where $M_{B}$ is the molecular weight of solvent (water in this case), $\varphi$ is the correlation coefficient of solvent, which is equal to 2.26 , and $\mathrm{V}_{\mathrm{A}}$ is the molar volume of the soluble, which can be obtained from $v_{c}$ and can be seen in the Table 1.

$$
v_{A}=0.285\left(v_{c}\right)^{1.048}
$$

To calculate the mass transfer coefficient $(\mathrm{k})$, the dimensionless number of Sherwood (Sh) is used:

$$
k=\frac{S h \cdot D_{A B}}{d_{p}}
$$

Where the Sherwood number can be obtained from [24]:

$$
S h=0.38 \mathrm{Re}^{0.83} S c^{1 / 3}
$$




\section{Results and discussion}

\subsection{Time effect}

The extraction time in the method of extraction with superhot water is short. To extract compounds from plant samples or investigate the environmental samples, in $5 \mathrm{~min}$ to $2 \mathrm{hr}$ in a dynamic state and 5-10 $\mathrm{min}$ in a static state, suitable efficiency can be achieved [3]. By increasing the extraction time, the efficiency will increase up to a constant value. The extraction time depends on the kinetics of the process and the time needed to reach the equilibrium. It is expected that by increasing the extraction time, the efficiency increases. The effect of time on the extraction of hydrocarbons or multiple-ring aromatic is shown in Figures $(1,2)$.

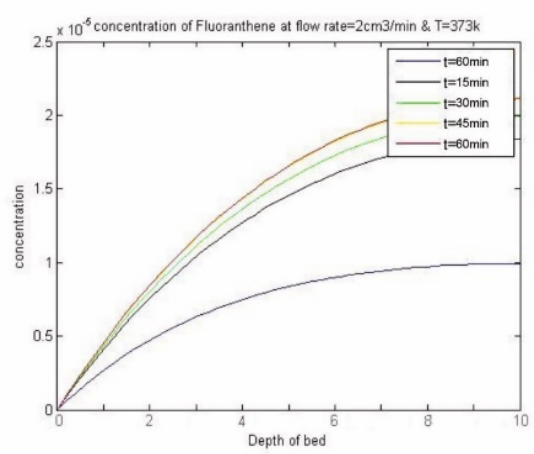

Fig. 1. Changes of fluoranthene concentration along the tower at different times at $373 \mathrm{~K}$.

As it is obvious, by increasing the extraction time, the concentrations of hydrocarbons in the liquid phase are increased. In fact, from a specific time to further, there is no change in the curve by increasing the time, which means it reached equilibrium. Also, it can be concluded that by increasing the time, the change rate of concentration increases, which can be ascribed to the contact time of two phases. In other words, the sufficient time needed for mass transfer is provided by further increasing the extraction time.

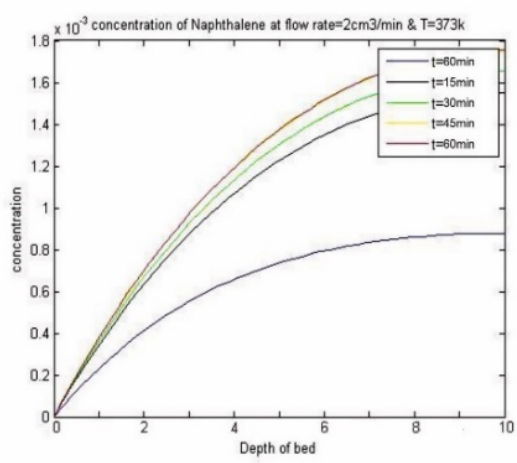

Fig. 2. Changes of pyrene concentration along the tower at different times at $373 \mathrm{~K}$.

\subsection{Flow rate effect}

The intensity of extraction enhances by increasing the flow rate. It is expected that a more flow rate can mitigate the resistance of the fluid phase. Thus, the amount of mass transfer from the solid phase to the fluid phase increases. In the following figures (Figures (3-6)), the effect of changes in flow rate in the range of $0.5-2 \mathrm{~cm}^{3} / \mathrm{min}$ is shown for the four mentioned compounds.

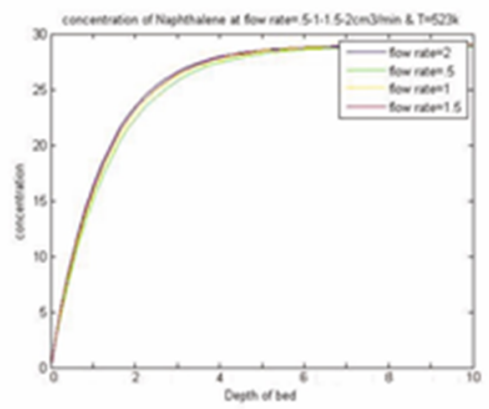

Fig. 3. The effect of flow rate on the concentration of phenanthrene.

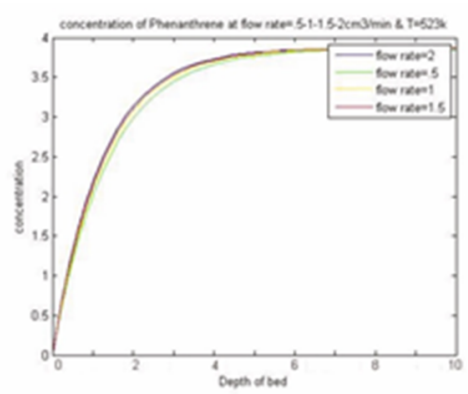

Fig. 4. The effect of flow rate on the concentration of fluoranthene.

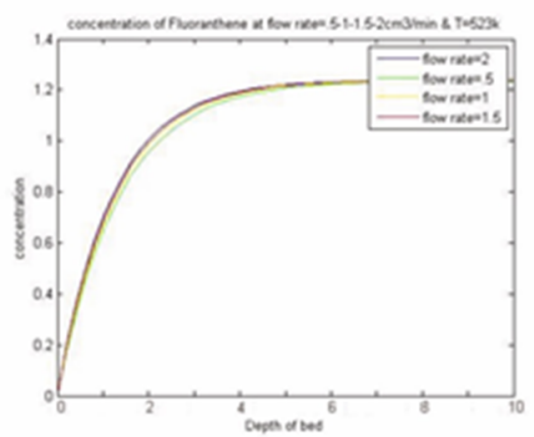

Fig. 5. The effect of flow rate on the concentration of naphthalene.

As can be seen in Figures, the variation of flow rate is not determinative on the amount of concentration. Also, for various compounds, there is no significant change in concentration, which can be concluded that the main resistance against mass transfer is the internal resistance, no 
the external one. In other words, the diffusion in the solid phase and reaching to surface, feel the most resistance. Overall, the resistance of the liquid phase is negligible.

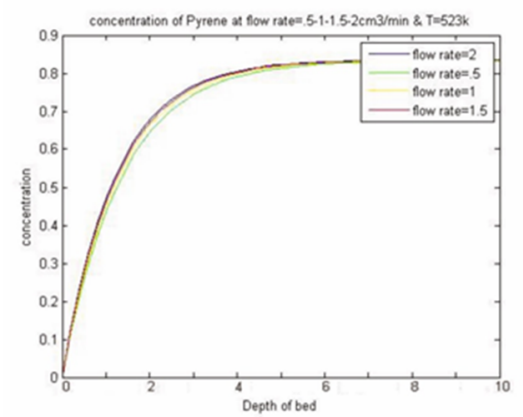

Fig. 6. The effect of flow rate on the concentration of pyrene.

\subsection{Temperature effect}

The most important parameter that affects the super-hot water system is temperature because by changing the temperature of the solvent (water), its properties will change $[11,39,40]$. By increasing the temperature, the surface tension and viscosity decrease, whereas the diffusion of the soluble compounds in the water enhances. In other words, more sufficient mass transfer will be provided by increasing the temperature, which can improve the extraction efficiency. This phenomenon is even more important in weak-polar or non-polar compounds because their solubility in water is negligible in low temperatures. Temperature can affect the solubility in water, axial distribution coefficient, and diffusion coefficient. So, significant changes in concentration are expected by varying the temperature. At the $25^{\circ} \mathrm{C}$ temperature, as can be seen in the previous section, water has a weak capability to dissolve these kinds of hydrocarbons. As the temperature increases, the dielectric constant decreases, and consequently, the solubility increases. Therefore, it is expected that by increasing the temperature, the solubility of this group of hydrocarbons in the liquid phase enhances.

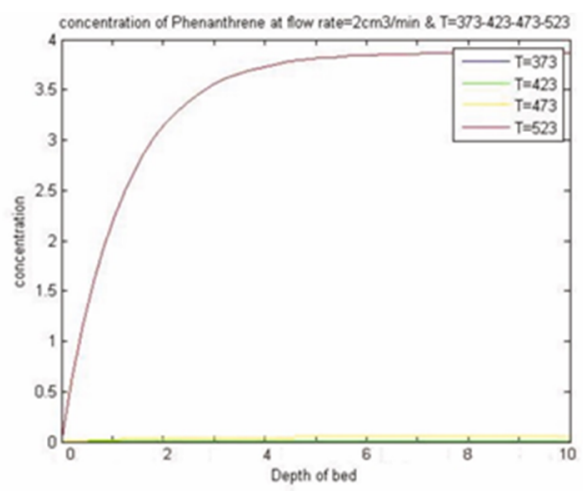

Fig. 7. The effect of temperature on the concentration of phenanthrene.

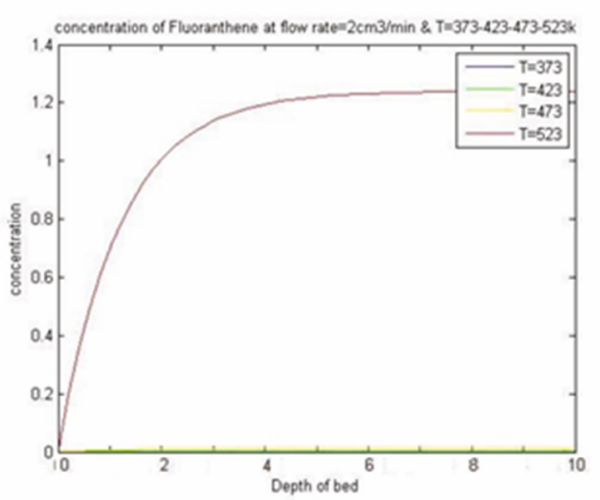

Fig. 8. The effect of temperature on the concentration of fluoranthene.

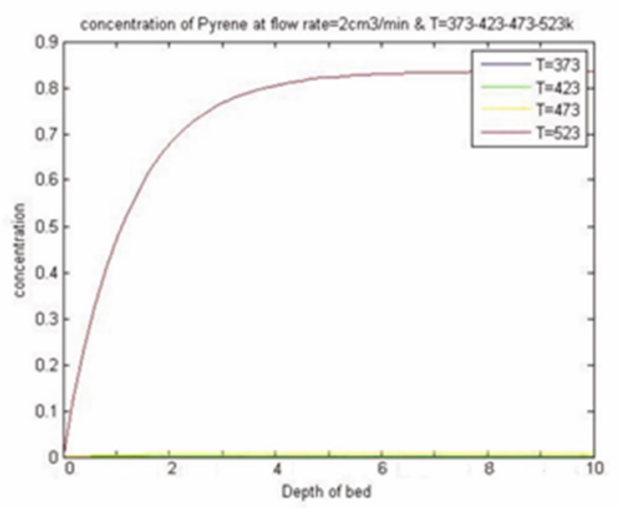

Fig. 9. The effect of temperature on the concentration of pyrene.

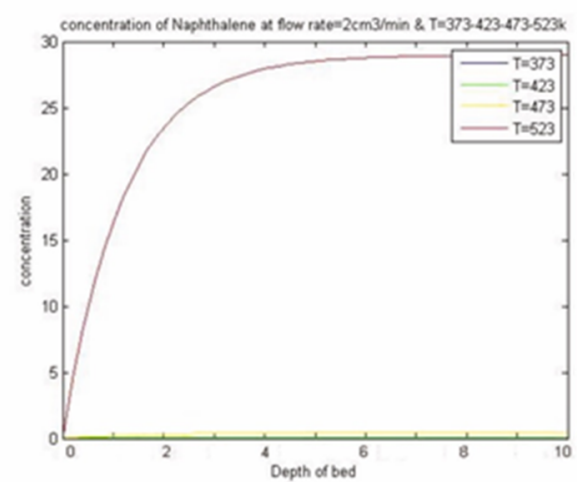

Fig. 10. The effect of temperature on the concentration of naphthalene.

As shown in Figures, by increasing the temperature ranging from 200 to 250 , the concentration variations were significantly affected. This phenomenon can be assigned to the effect of these compound's solubility, which by increasing the temperature, the solubility enhances significantly, and this is obvious in Figures. 
The following figure provides a comparison between the concentration changes of the four compounds at $2 \mathrm{~cm}^{3} / \mathrm{min}$ flow rate and $150^{\circ} \mathrm{C}$ temperature. As can be seen in Figure, the concentration changes of naphthalene are more than others, and phenanthrene, fluoranthene, and pyrene come next, respectively. This order exactly originates from their solubility which is in the order of naphthalene, phenanthrene, fluoranthene, and pyrene, from higher to lower. On the other hand, the molecular weight of naphthalene is lower than others, which influences on its diffusivity in the liquid phase.

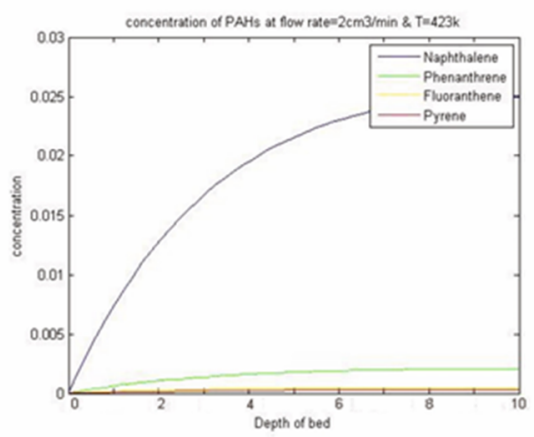

Fig. 11. A comparison between the concentration changes of the four compounds.

\subsubsection{Review of experimental studies}

This review is done for the compounds of naphthalene and phenanthrene [41].

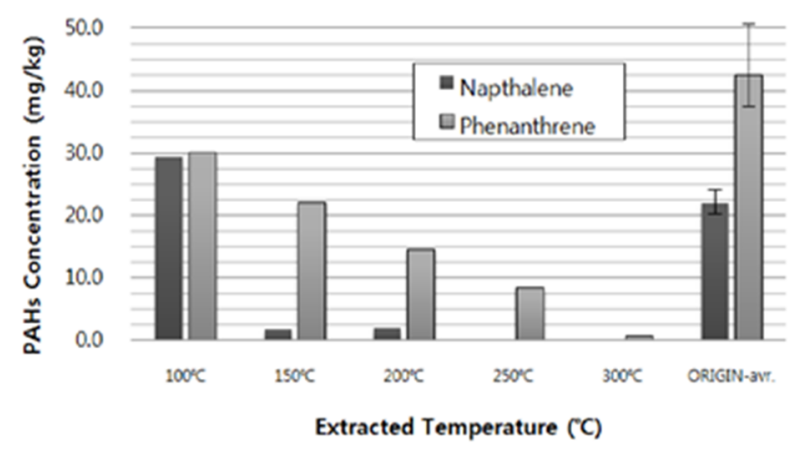

Fig. 12. Comparing the concentration of naphthalene and phenanthrene in the initial soil and the treated soil.

The concentrations of remaining naphthalene were 29 , $1.8,1.9,0$, and $0 \mathrm{ppm}$, at 100, 150, 200, 250, and 300, respectively. This means that the concentration of remaining naphthalene at 100 degrees, is slightly more than its concentration in the initial soil, and at 150 degrees, is significantly decreased to a value of $2 \mathrm{ppm}$. This evidences that the extracted naphthalene does not separate from soil in $100{ }^{\circ} \mathrm{C}$. But, over $150^{\circ} \mathrm{C}$, it will be easily separated from the soil. There are some other reasons that why naphthalene does not separate from the soil at $100^{\circ} \mathrm{C}$. One of them is that the physical properties of soil up to $100{ }^{\circ} \mathrm{C}$ temperature and 100 atm pressure will change, and this variation can cause a change in the separation fraction of methanol from the soil and subsequently will affect the separation of remaining naphthalene from the soil. As another reason, the lack of homogeneity in the concentration of initial soil, which is heated up to $100 \mathrm{n}{ }^{\circ} \mathrm{C}$, can be mentioned. The concentration of remaining naphthalene was also decreased from $30 \mathrm{ppm}$ at $100{ }^{\circ} \mathrm{C}$, to $0.74 \mathrm{ppm}$ at $300{ }^{\circ} \mathrm{C}$. As can be seen in Figure 2 , the separation of phenanthrene from the soil needs more heat than the value needed for naphthalene, which originates from the properties of phenanthrene that, in comparison with naphthalene, has a lower solubility in water and higher molecular weight and melting point.

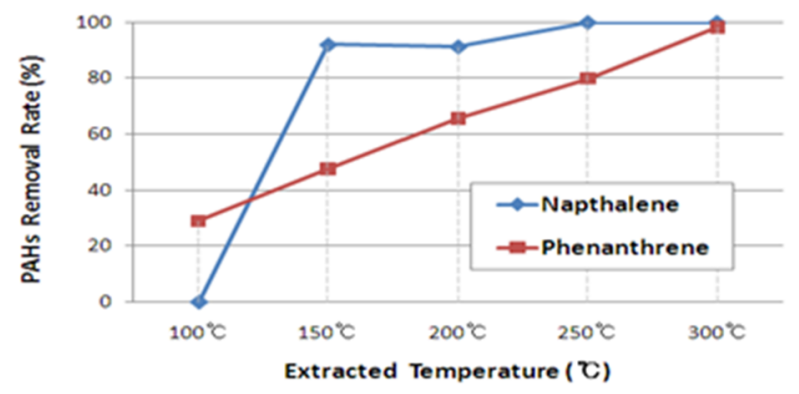

Fig. 13. The percentage of clearing soil from pollutants in different temperatures.

To clear a naphthalene-contaminated soil, $150{ }^{\circ} \mathrm{C}$ is sufficient. To clear a soil polluted with PAHs such as phenanthrene, anthracene, etc.

\section{Conclusions}

No need for organic solvent or negligible assumption of organic solvent is the most prominent characteristic of extraction with super-hot water. Accessibility, low-cost, and non-toxicity of water as the main solvent, and no need for drying the wet samples are other characteristics of this method. In many cases, this method in comparison with other methods, is more clear, cheaper, and faster. Extraction with super-hot water has showed lots of benefits in term of no need for organic solvents in environmental extractions. The equipment needed for this method is relatively simple and there is no need for applying high pressures, as the extraction with supercritical fluid. In this study, a simple mathematical model was presented for the fluid phase, which evaluated the extraction efficiency in terms of temperature, time, and flow rate. Also, the amount of concentration changes for naphthalene, phenanthrene, fluoranthene, and pyrene were measured with the parameters of temperature, flow rate, and time. Among these parameters, temperature was the most determinative one, and the amount of extraction is increased by increasing the temperature. It can be mentioned that almost $95 \%$ naphthalene was extracted at 100 bar. Because naphthalene 
was resistant in soil at $100{ }^{\circ} \mathrm{C}$ and does not separate from the soil, but at $150{ }^{\circ} \mathrm{C}$ and higher temperatures, due to its physical properties, which is changed in this condition, it can be easily separated from soil. As in this study, significant changes in concentration were observed in the temperatures of 200 and $250{ }^{\circ} \mathrm{C}$, which is ascribed to the effect of solubility of these compounds that increases by increasing the temperature. Also, the variation of flow rate has a negligible effect on the concentration for all compounds, which means that the internal resistance is determinative, comparing with the external one. In other words, the diffusion in the solid phase and reaching to the surface feel the most resistance. Overall, the resistance of the liquid phase is negligible. By increasing the extraction time, the rate of concentration changes increases, which can be assigned to the contact time between two phases. By a meaning, sufficient time for mass transfer can be provided by increasing the time. Short extraction time, high-quality extract, low cost of indicators needed for extraction, and compatibility with the environment are other prominent characteristics of this method.

\section{Limits and suggestions}

According to this fact that the solvent used in the extraction with super-hot water is water, the more assumption of water comparing with other methods can be mentioned as one of the disadvantages of this method, which is suggested that to overcome this issue in future studies, this should be included in the technical and economical calculations.

Also, as one of the limits of this method, high temperature and pressure can be mentioned, which can be a serious drawback regarding utilizing this method in more wide applications, so it is needed to be studied more.

Corrosion is also another important factor that should be considered. For example, stainless steel, as one of the most applicable material that is usually used in the equipment of super-hot water is corroded. So, for dealing with super-hot water, utilizing special materials is needed, which are more expensive than common materials in the industry. According to the discussed contents, it is hoped that the existing problems to be solved or mitigate in future studies, to facilitate the more application of this technology in industry.

\section{References}

1. N. Rangzan, Investigation of the effect of petroleum hydrocarbon pollutants (diesel) on some physical and chemical properties of contaminated soil, Master Thesis, Faculty of Agriculture, Shahid Chamran University, Ahva, 2006

2. C. Cupers, T. Pancras, T. Grotenhuis, W. Rulkens. The estimation of PAH bioavaiability in contaminated sediments using hydroxypropyl-B cylodextrin and triton $\mathrm{x}-100$ extraction techniques. J. Chem. 46, 123545 (2002)

3. A. Rababah, S. Matsuzawa. Treatment system for solid matrix contaminated with fluoranthene 11 recirculating photodegradation techniques. J. Chem. 46, 49-57 (2002)

4. Http://Hamedanzist.parsiblog.com/Post/23

5. Agency for Toxic Substances and Disease Registry (ATSDR), Polycyclic Aromatic Hydrocarbons, in Public Health Statement (U.S. Department of Health and Human Services U.S. Public Health Service, Atlanta, 1990)

6. Interalaboratory Comparison Stunt: Methods for volatile and semi-volatile compounds, Environmental monitoring systems laboratory, office of research and development, EPA. 600/4- 84- 027 (U. S. EPA., Las Vegas, NV, 1984)

7. Basaltpour, A. İ Haj Abbasi, M, AS; The eloquent character of A.H. and opium M. 1387. Investigation of Oil Soil Contaminated Soils by Phytoremediation Method, Journal of Agricultural Sciences and Natural Resources, Volume 15, Number 4.

8. Roger M. Smith, Extractions with superheated water. J Chromatogr A. 975, 31-46 (2002)

9. Terhi Andersson, Parameters Affecting the Extraction of Polycyclic Aromatic Hydrocarbons with Pressurised HotWater, Doctoral thesis, University of Helsinki, Helsinki, 2007

10. Eng Shi Ong, Jane Si Han Cheong, David Goh, Pressurizedhot water extraction of bioactive or markeer compounds inbotanical and medicinal plant materials. J Chromatogr A. 1112, 92-102 (2006)

11. Z. Pineiro, M. Palma, C.G. Barroso, Determination of catechins by means of extraction with pressurized liquids. J Chromatogr A. 1026,19-23 (2004)

12. Selective subcritical water extraction of aromatic andaliphatic organic pollutant $\mathrm{s}$ from petroleum industrysoils and sludges (API Publication No.4, July 1998)

13. L. Haar, J.S. Gallagher, National Bureau of Standard/National Research Council Steam Tables (Hemisphere Publishing Corporation, 1984)

14. IAPWS R8-97, Release on the Static Dielectric Constant of Ordinary Water Substance for Temperatures from $238 \mathrm{~K}$ to $873 \mathrm{~K}$ and Pressures up to $1000 \mathrm{MPa}$, September 1997

15. Alena Kubátová, Boris Jansen, Jean-François Vaudoisot, Steven B Hawthorne, Thermodynamic and kineticmodels for the extraction of essential oil from savory andpolycyclic aromatic hydrocarbons from soil with hot(subcritical) water and supercritical CO2. J Chromatogr A. 975, 175-188 (2002)

16. Fereshteh Golmohammad, Mohammad Hassan Ikani, Soheila Shokrollahzadeh, A Review of Hot Water 
Extraction and Extraction of Medicinal Plants. Quarterly Journal of Medicinal Plants (2008)

17. Zontag, Borgnak, Van Wyllen, "Classical Thermodynamics", Fourteenth Edition, Fifth Edition, translated by Malekzadeh - Engineer Kashani Hesar Motamedi

18. J.E. Cacace, G. Mazza, Pressurized low polarity water extraction from whole flaxseed. J. Food Eng. 77, 10871095 (2006)

19. E.S. Ong, J.S.H. Cheong, D. Goh, Pressurized hot water extraction of bioactive or marker compounds in botanicals and medicinal plant materials. J Chromatogr A. 1112, 92-102 (2006)

20. O.M. Ogunsola, N. Berkowitz, Extraction of oil shales with sub- and near- critical water. Fuel Processing Technology 45, 95-107 (1995)

21. D.D. Williams, M.K. Lee, J.L. Crawford, P.O. Tyree, Analysis of convective heat transfer in deformed and stratified aquifers associated with Frasch thermal mining. Ground Water 37, 517-522 (1999)

22. S.B. Hawthorne, Y. Yang, D. J. Miller, Anal. Chem. 66 (1994)

23. Y. Yang, S. Bøwadt, S. B. Hawthorne, D.J. Miller, Anal. Chem. 67 (1995)

24. Mass Transfer: Advances in Sustainable Energy and Environment Oriented Numerical Modeling, ed. by Hironori Nakajima (2013)

25. A.J.M. Lagadec, D.J. Miller, A.V. Lilke, S.B. Hawthorne. Environ. Sci. Technol. 341542 (2000)

26. Selective subcritical water extraction of aromatic andaliphatic organic pollutant $\mathrm{s}$ from petroleum industry soils and sludges (API Publication No.4 July 1998). 